\title{
Heuristic Teaching Method of Discrete Mathematics based on the Mathematical Games
}

\author{
Yu-ming $\mathrm{MA}^{1, \mathrm{a},{ }^{*}}$ \\ ${ }^{1}$ School of Information Science, Qilu University of Technology, Jinan, China \\ amym@qlu.edu.cn
}

Keywords: Heuristic teaching method, Discrete mathematics, Mathematical games.

\begin{abstract}
Discrete mathematics courses is one of the core curriculums for the computer professional, The content of discrete mathematics is abundant and abstract, some concepts and functions is hard to understand for students. In this paper, we proposed a heuristic teaching method based on the mathematical games to solve problems in the teaching of discrete mathematics. The use of mathematical games in class encourages active learning, as well as collaboration and interactivity. This method can improve the learning enthusiasm of students, and make abstract content easy to be understood and remembered.
\end{abstract}

\section{Introduction}

Discrete mathematics courses is one of the core curriculums for the computer professional, it is the theory basis for computer science and technology and play an important role in the computer science research. The course will not only offer basic mathematical theory for students to learn follow-up courses, but also help develop the logic thinking ability, problem-discovering and problem-solving potentials. But the result of teaching practice about it is not as satisfactory as expected during these years [1].

There are several reasons for this problem. The content of discrete mathematics is abundant and abstract, some concepts and functions is hard to understand for students [2].Direct and simple coaching methods are used in process of teaching. As a result, some students feel that the discrete mathematics is boring, so as to lose interest in learning. Elbert Einstein said, interest is the best teacher, students with proper interest in learning will be more concentrated on class sessions, and they will also spend more time and make more efforts to learn.

Although we have teaching means help students to master knowledge and improve their abilities, more important is how to stimulate students interest in learning. This is always a challenging problem for teachers.

\section{Heuristic Teaching Method}

Heuristic teaching method is one of the most important teaching methods nowadays. What is Heuristic teaching method?

Heuristic teaching method refers to a teaching method that the instructor raises questions and solves problems from the shallower to the deeper, from the near to the distant, from the outside to the inside and from the easier to the more advanced and leads students to grasp the knowledge actively, positively and consciously according to the textbook contents and student's cognitive rules. The essence of the heuristic 
teaching method should be guidance and it is the specific embodiment of the educational concept of "giving priority to learning".

Discrete mathematics is difficult for students, because the concepts purely mathematically with little or no visible application to computer science. Heuristic teaching method is appropriate to this course to help students study it actively [3]. How to apply heuristic teaching method in discrete mathematics teaching?

\section{Mathematical Games}

Everyone loves games, and games are playing a more central role in peoples' lives than ever before. The use of games in class encourages active learning, as well as collaboration and interactivity. Games can also provide educators with an interactive means of delivering knowledge that is particularly useful for teaching cause and effect [4]. This method is not only suitable for primary school students, middle school students, but also for college students. In order to stimulate student's interest in learning discrete mathematics we utilize the mathematical games to perform heuristic teaching.

Mathematical games as a puzzle game can arouse people's enthusiasm and challenge. There has been a long history of the use of games specifically for mathematical learning. The relationship between mathematics and gaming has been often used as a means for motivating students [5][6].

\section{The Use of Mathematical Games in Discrete Mathematics Teaching and Learning}

The teaching content of discrete mathematics generally include following four sections [7]: set theory, mathematical logic, algebra system, and graph theory. Set theory is the basis for both mathematics and discrete mathematics. Mathematical logic studies mathematical reasoning rules. Algebraic system is to study the calculating rules of math. Graph theory studies abstract mathematical structure rules. Some concepts, theorems and formulas can be associated with mathematical games [8].

Example 1 An island has two kinds of inhabitants, knights, who always tell the truth, and their opposites, knaves, who always lie. You encounter two people A and B. What are A and B if A says knave and B says "The two of us are opposite types"?[9]

Solving logic puzzles is an excellent way to practice working with the rules of logic. Example 1 associated with Mathematical logic.

Solution: Let $\mathrm{p}=$ "A is a knight", q="B is a knight".

First, if $\mathrm{p}$ is true, i.e. A is a knight; If $\mathrm{A}$ is a knight, then he is telling the truth, then $\mathrm{B}$ is a knight too, A and B are the same type. However, if B is a knight, then B's statement that $A$ and $B$ are of opposite types, the statement $(p \wedge \neg q) \vee(\neg p / q)$, would have to be true, which it is not, because $\mathrm{A}$ and $\mathrm{B}$ are both knights. So, assumption about $\mathrm{p}$ is wrong i.e. $\mathrm{A}$ is a knave.

Second, if A is a knave, "B is a knight" is a lie, which means that $\mathrm{q}$ is false and B is also a knave. Furthermore, if B is a knave, then B's statement that A and B are opposite types is a lie, which is consistent with both $\mathrm{A}$ and $\mathrm{B}$ being knaves. We can conclude that both $\mathrm{A}$ and $\mathrm{B}$ are knaves.

Example 2 The town of Königsberg, Prussia was divided into four sections by the branches of the Pregel River. These four sections included the two regions on the banks of the Pregel, Kneiphof Island, and the region between the two branches of the Pregel. In the eighteenth century seven bridges connected these regions. Figure 1(a) depicts these regions and bridges. The town's people took long walks through town on Sundays. 
They wondered whether it was possible to start at some location in the town, travel across all the bridges without crossing any bridge twice, and return to the starting point. whether it was possible?

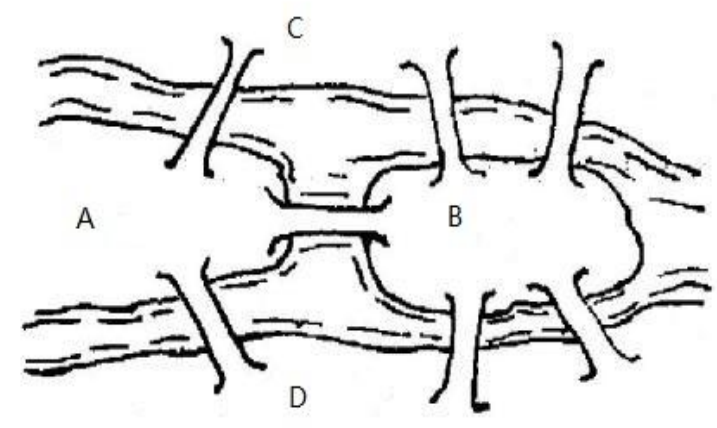

(a)

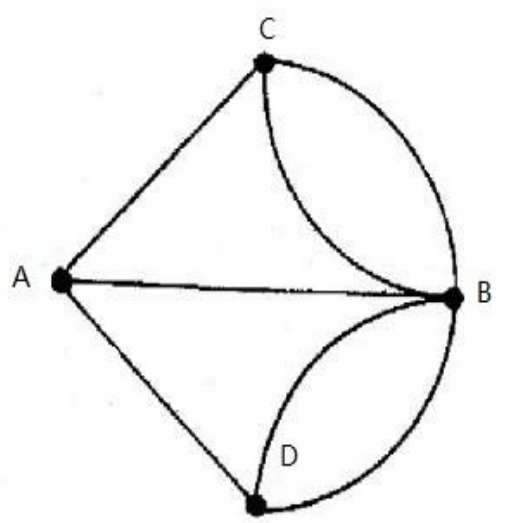

(b)

Figure 1. (a)The seven Bridges of Königsberg, (b)Graph model of The seven Bridges

The Swiss mathematician Leonhard Euler solved this problem. he replaced the map of Königsberg with the general graph G drawn in Figure 1(b), this problem is determine whether there exists a closed trail that contains all the edges of $\mathrm{G}$.

Example 3 Icosian puzzle is invented in 1857 by the Irish mathematician Sir William Rowan Hamilton [10]. It consisted of a wooden dodecahedron, with a peg at each vertex of the dodecahedron, and string, shown in Figure 2(a). The 20 vertices of the dodecahedron were labeled with different cities in the world. The object of the puzzle was to start at a city and travel along the edges of the dodecahedron, visiting each of the other 19 cities exactly once, and end back at the first city.

The equivalent question: Is there a circuit in the graph shown in Figure 2(b) that passes through each vertex exactly once? This solves the puzzle because this graph is isomorphic to the graph consisting of the vertices and edges of the dodecahedron. A solution of Hamilton's puzzle is shown in Figure 2(c).

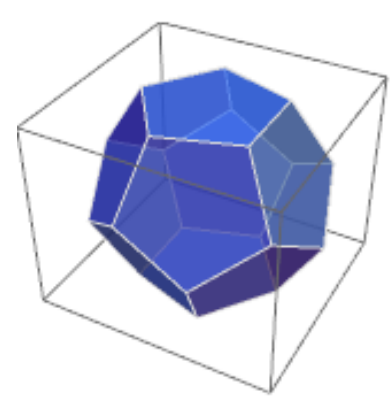

(a)

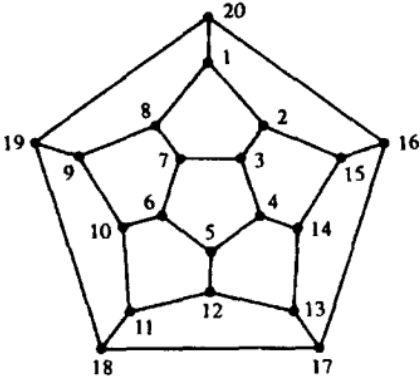

(b)

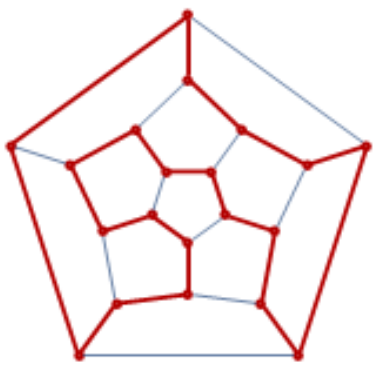

(c)

Figure 2. (a) the dodecahedron(b)Graph model of Hamilton's puzzle (c) A solution of Hamilton's puzzle

\section{Conclusions}

Discrete Mathematics as a powerful mathematical tool for the development of computer and computer science research plays an important role; however, there are some problems in the teaching process. The interests of student in learning discrete mathematics should be stimulated as much as possible. Students with proper interest in learning will be more concentrated on class sessions, and they will also spend time and 
make efforts to learn. In the paper, we proposed a heuristic teaching method of discrete mathematics based on mathematical games. This method can improve the learning enthusiasm of students, and make abstract content easy to be understood and remembered.

\section{References}

[1] Zhang Y, Zhang H. Discussion Reform of Education on Course of Discrete Mathematics[C].ICETMS. 2013:21-24.

[2] Zhihua Gao, Kerong Ben, Xia Liu. Discrete Mathematics Course Content and Discussion of Learning Method [J]. Computer Education, 2011(13):107-109

[3] Ginat D. Elaborating heuristic reasoning and rigor with mathematical games [J]. 2007, 39(4):32-36.

[4] Afari E. Teaching mathematics in game learning environment. [J]. Uob.edu.bh, 2012, 1(1):33-45.

[5] Xia Y Q, Wang Q J. On Function of Mathematical Recreation [J]. Journal of Liaoning Normal University, 2002, 25(1):106-109.

[6] Powell J A, Harris A M. Games to Teach Mathematical Modelling [J]. Siam Review, 1998, 40(40):87-95.

[7] Jiepan $\mathrm{Xu}$. Foundation Course of Discrete Mathematics [M]. Beijing: China Machine Press, 2009

[8] Lifang Wang, Jinguang Wang. The Application of Pleasant Education Mode for Student Interests in Discrete Mathematics [J].China Electric Power Education,2011(8): 92-93

[9] Rosen K H.Discrete Mathematics and Its Applications [M]. Sixth Edition, New York: The McGraw-Hill Companies, Inc, 2007.

[10] Information on http://blog.csdn.net/yuan_zhijiang/article/details/40538233 